\title{
Silk Device for the Treatment of Intracranial Aneurysms. Part 1: Peri-Procedural Results, Technical Aspects and Learning Curve
}

\author{
Erdem GURKAS ${ }^{1}$, Tunca KAYA², Ergun DAGLIOGLU ${ }^{3}$, Ilkay AKMANGIT ${ }^{2,4}$, Deniz BELEN ${ }^{3}$, Ahmet PEKER ${ }^{4}$, \\ Dogan DEDE ${ }^{2}$, Anil ARAT ${ }^{2,4}$
}

${ }^{1}$ Ankara Numune Training and Research Hospital, Department of Neurology, Ankara, Turkey

${ }^{2}$ Ankara Numune Training and Research Hospital, Department of Radiology, Ankara, Turkey

${ }^{3}$ Ankara Numune Training and Research Hospital, Department of Neurosurgery, Ankara, Turkey

${ }^{4}$ Hacettepe University, School of Medicine, Department of Radiology, Ankara, Turkey

\section{ABSTRACT}

AIM: We evaluated the procedural outcomes of intracranial aneurysm treatment with the Silk device and its relation with operator experience. We also detailed some technical points we learned throughout our experience.

MATERIAL and METHODS: One hundred and six consecutive patients with intracranial aneurysms treated using Silk (BaltExtrusion, Montmorency, France) stent between October 2010 and November 2013 were included. Patients were evaluated in terms of age, sex, aneurysm size, location, technical success, and adverse events.

RESULTS: There were 106 patients (71 female) undergoing 116 procedures with a mean age of 49.8 (range: 3-78 years). Mean aneurysm size was $10.7 \pm 8.0$ (range, $2-40 \mathrm{~mm}$ ). Technical success of the procedures was $96.5 \%$. Adverse event rate was $11.2 \%$. Among adverse events, there were 4 adverse events without complications, 2 mild complications, 7 severe complications, 4 of which resulted with death. The adverse event rate was significantly higher during the first half of the operator's experience. The rate of adverse events seemed to stabilize after around 50 patients. Adverse events, regardless of the presence or absence of a clinical complication, were more frequent in aneurysms larger than $18.5 \mathrm{~mm}$.

CONCLUSION: Safety of flow-diverter (FD) placement for intracranial aneurysms increases with operator experience. Training programs in endovascular management of cerebrovascular diseases and relevant fellowship curricula must be adapted to include sufficient flow diverter experience. The learning curve needs to be kept in mind when studies comparing different FD devices or those comparing other treatments to FDS are planned.

KEYWORDS: Silk device, Intracranial aneurysm, Peri-procedural, Technical aspect, Learning curve

\section{INTRODUCTION}

Endovascular aneurysm embolization with coils have been criticised for inability to achieve durable aneurysm exclusion when compared to surgical clipping. With coil embolization, this is valid especially for large and wide neck aneurysms that cannot be occluded completely during the procedure and at follow-up they usually show high rates of re-canalization $(8,27)$.
Failure of these treatments led the physicians and the industry to investigate new techniques for better success rates to treat these large complex aneurysms. With the development of low-profile microcatheter-delivered self-expanding stents, intracranial parent artery reconstruction became feasible. Initially used technique was stent assisted coiling that resulted in better packing of the coils. With stenting, recurrence rates 
decreased although it still remained as a problem. Flow-diverter (FD) devices were designed to decrease the aneurysmal filling so that thrombosis formation inside the aneurysm could be facilitated. Then with the formation of the neo-intima along the neck, aneurysm is excluded from the circulation (25).

In this study, we evaluated the safety and early outcomes of the Silk endovascular device (SED) in the treatment of intracranial aneurysms. We also evaluated the technical aspects and the learning curve, an issue that was not previously highlighted for Silk device. We also detailed the techniques and methods we learned throughout this learning curve.

\section{- MATERIAL and METHODS}

\section{Subject and Methods}

This is a retrospective study evaluating patients with intracranial aneurysms treated with Silk (Balt Extrusion, Montmorency, France) stent by a single neurovascular team between October 2010 and November 2013. 106 consecutive patients treated with 116 successful or unsuccessful procedures were included in this study. These patients were considered in terms of age, sex, aneurysm size, location, procedural success, adverse events.

\section{Dual Antiplatelet Therapy}

$75 \mathrm{mg}$ clopidogrel and $300 \mathrm{mg}$ acetyl salicylic acid were initiated at least 5 days prior to procedure. Patients with subarachnoid hemorrhage (SAH) who needed urgent operation were given either loading dose of $600 \mathrm{mg}$ clopidogrel prior to procedures or intravenous Aggrastat (DSM Pharmaceuticals, Inc. Greenville, North Carolina, USA) during the procedure, continued with 24 hour Aggrastat infusion with a loading dose of $600 \mathrm{mg}$ clopidogrel. For the maintenance treatment after the procedures, all patients continued with $300 \mathrm{mg}$ acetyl salicylic acid and $75 \mathrm{mg}$ clopidogrel once daily for 6 months. After routine control at 6 months, treatment continued with $300 \mathrm{mg}$ acetyl salicylic acid alone.

\section{Endovascular Procedures}

All procedures were performed under systemic heparinization and general anesthesia using monoplane (Innova $4100 \mathrm{GE}$ Healthcare, Wisconsin, USA, Siemens Multistar, Erlangen, Germany) or biplane (Artis Zee Siemens, Erlangen, Germany) digital subtraction angiography (DSA) machines. Parent artery and aneurysm sizes were measured using 2D and 3D images.

2-5 ml of intraarterial Nimodipine (Nimotop, Bayer, Newbury, Berkshire, UK) was infused in the parent artery after placement of a 6 Fr guiding sheath (Penumbra Neuron, Penumbra Inc, Harbor Bay Pkwy Alameda, CA, USA, Epsylar Ettlingen, Germany or Flexor shuttle guiding sheath, Cook Medical INC. Bloomington, IN, USA) via the transfemoral route. Then a distal access catheter [Fargo mini (Balt Extrusion, Montmorency, France), DAC 44 (Concentric Inc, Kalamazoo, Michigan, USA), Fargo / Fargo Max (Balt Extrusion, Montmorency, France) or Neuron (Penumbra Inc, Harbor Bay Pkwy Alameda, CA, USA)] was advanced to a secure point in the parent artery. Either Vasco+21 or Vasco+25 (Balt Extrusion, Montromercy, France) was chosen according to the planned size of the stent, and then was navigated distal to the aneurysm with a floppy microguidewire. When the stent reached the desired segment, the techniques explained below were used for the initial deployment:

1. The stent was deployed partially by unsheathing, similar to the deployment of a laser-cut stent, in order to prevent the forward movement of the stent (Figures 1A, B), followed by direct push technique (Figure 2).
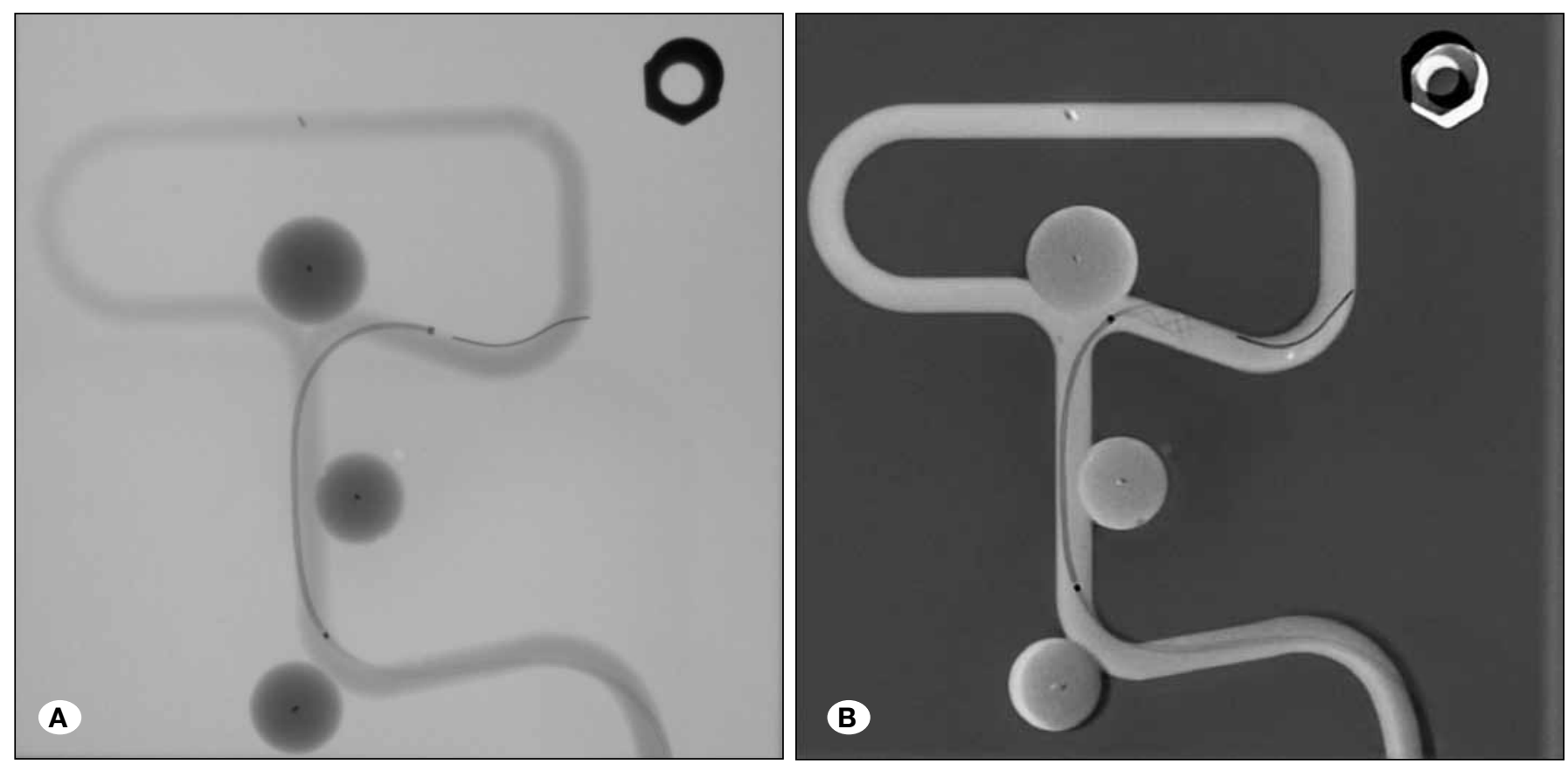

Figure 1A,B: Stent was deployed partially by unsheathing in order to prevent the forward movement of the stent. 


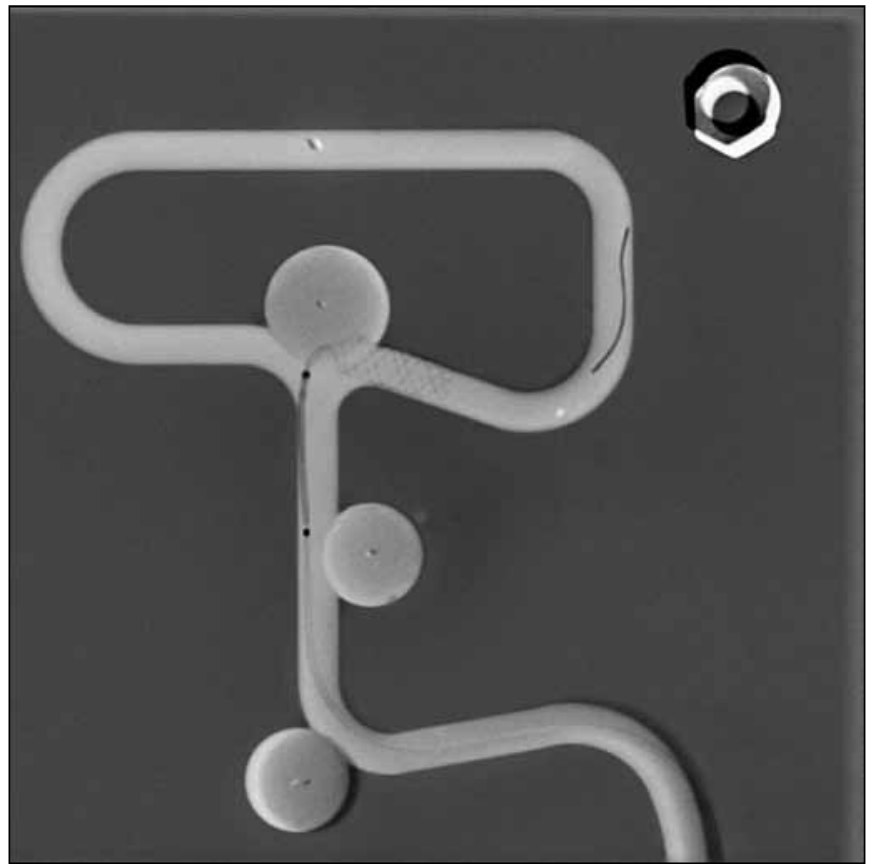

Figure 2: Direct push technique.
2. The stent was deployed partially with direct push-out technique (Figures 3A-C).

3. The microcatheter was placed distally in the parent vessel, the stent was deployed partially and then the partially opened stent was dragged proximally.

After initial deployment, the following techniques were used to deploy the body of the stent:

1. Direct push-wire technique

2. Sequential catheter unsheath and catheter-load technique: After each segment of the device is unsheathed. This segment is forced to expand by pushing/loading by the forward force applied to the delivery catheter. This is repeated for every segment until the stent is fully deployed. One must be careful not to intussuscept the device.

3. Stent was partially deployed in a relatively over-expanded fashion into the aneurysm and then the over-expansion was reduced by pulling the entire system back gently (Figure 4AC).

Stent apposition was evaluated by the 2D and 3D angiograms after the stent was deployed. If the stent was not apposed by
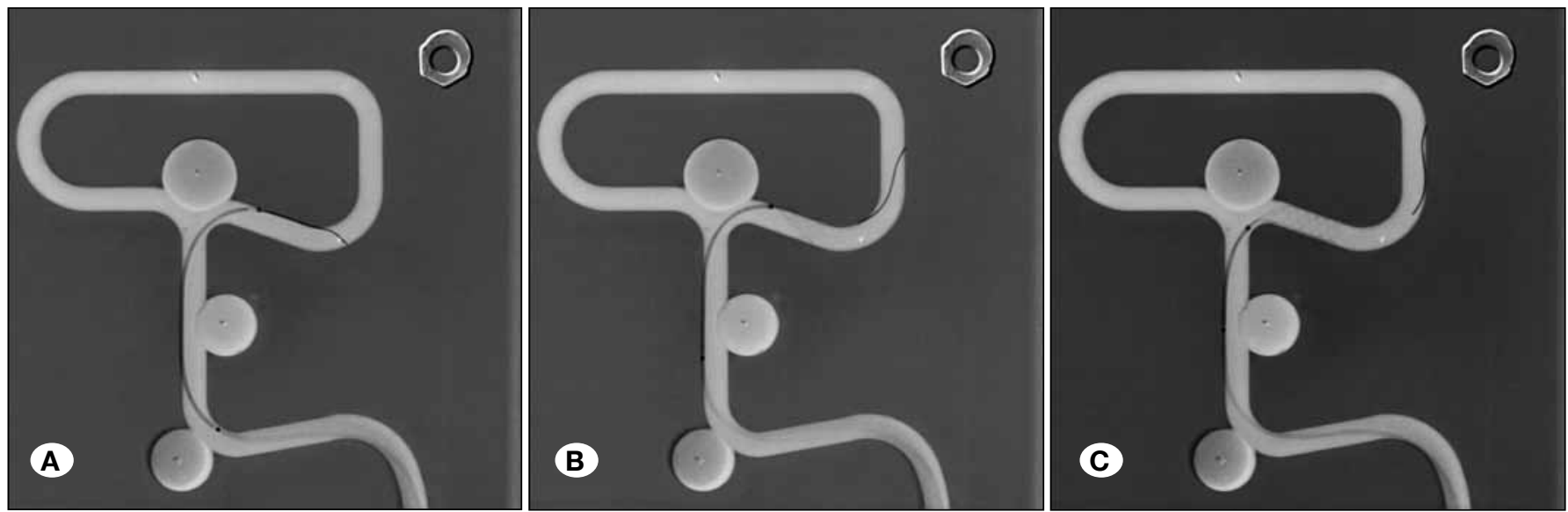

Figure 3A-C: Stent was deployed partially with direct push-out technique.
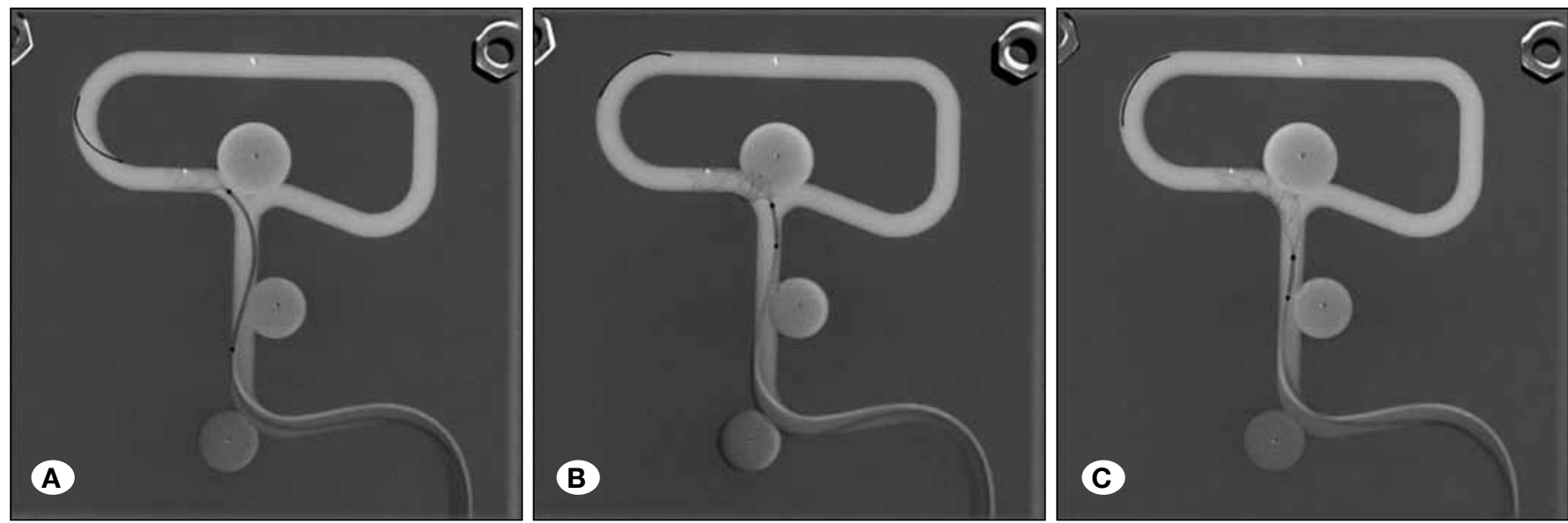

Figure 4A-C: Stent was partially deployed in a relatively over-expanded fashion into the aneurysm and then the over-expansion is reduced by pulling the entire system back gently. 


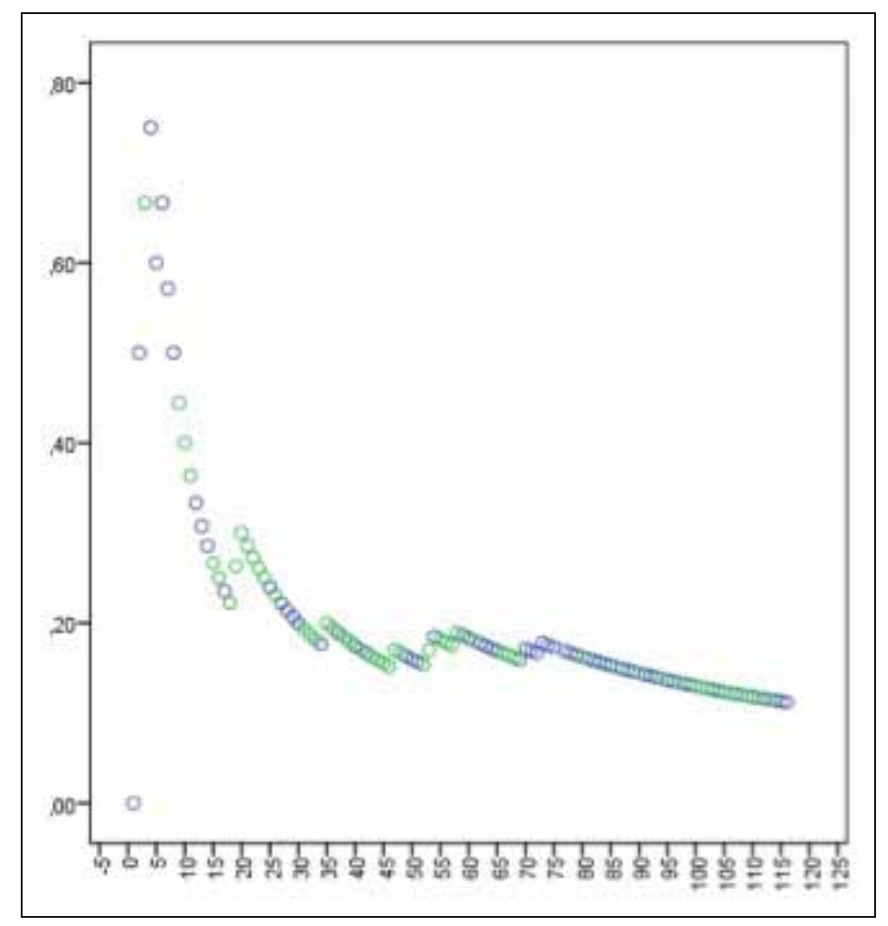

Figure 5: Learning curve plot. Vertical axis represents proportion of cases with adverse event by number of patients treated, horizontal axis represents number of patients treated.

the forward and backward movement of the stent wire, inner and outer wall apposition was achieved. If the apposition was not succeeded by these maneuvers, a microcatheter was passed through the stent and stretched and pushed to maintain inner and outer wall apposition.

\section{Follow-up}

All the patients were controlled at 1-3 months clinically and radiologically (Magnetic Resonance Imaging or Computed Tomography). At 6 months, radiological control with digital subtraction angiography (DSA) was performed. Only the clinical results of the patients till their discharge and the technical data regarding the procedures were included in this article.

\section{Statistical Analysis}

Analysis were made using IBM SPSS for Windows version 21.0. Quantitative variables were summarized with mean \pm standard deviation and median (min-max), qualitative variables were summarized by the number and percentage. To assess whether there is difference between two groups, t-test was used for independent variables in case of ensuring parametric test assumptions and Mann-Whitney $U$ test was used when parametric test assumptions were not met. Differences between the groups in terms of categorical variables were examined using chi-square test or Fisher's exact test. The power of the aneurysm size to determine presence of complications was determined by receiver operating characteristic (ROC) curve analysis. The significance level was accepted as $p<0.05$.
A learning curve was created by plotting cumulative proportion of cases with adverse event against number of patients treated (operator experience).

\section{RESULTS}

There were 106 patients (71 female and 35 male) undergoing 116 procedures with a mean age of 49.8 (range, 3-78 years). The data involved the time span between the admission of the patient and the time the patient was discharged. In one patient, the patient was readmitted 2 days following discharge due to deteriorating clinical status. The data regarding this patient's second admission was also included in this study. The follow-up findings about this patient cohort are included in Part 2 of this series. The mean aneurysm size was $10.7 \pm 8.0$ (range, 2-40 mm). Technical success of the procedures was $96.5 \%$. Adverse event rate was $11.2 \%$. Among these adverse events, there were 4 adverse events without complications, 2 mild complications, 7 severe complications, 4 of which resulted with death.

\section{Adverse Events}

Without clinical sequela: In one patient, a self-limiting carotid cavernous fistula, and in another patient a self limiting femoral arteriovenous fistula occurred. In one patient, a diffuse vasospasm at middle cerebral artery developed. In another patient, stent remained like hourglass shape and did not open any more but the patient remained asymptomatic.

With mild clinical sequela: One patient developed transient ischemic attack (TIA) with basilar artery perforating branch origin. One patient had post-procedural decrease in visual acuity.

With significant clinical sequela: Stroke occurred in 7 patients. Among 3 patients with total occlusion, one died due to cerebral infarction and 2 died due to hemorrhagic conversion of the cerebral infarction. In one patient, there was total occlusion of the ipsilateral middle cerebral artery (MCA) during the pre-procedural angiogram which was re-canalized partially with a stentriever, the aneurysm was treated successfully but the patient had severe hemiparesis on follow-up. One patient was discharged with disabling neurologic deficit and was later lost to follow up. One patient had a basilar perforator infarct and awakened from the procedure with hemiparesis. One patient had an arterial rupture during intra-arterial balloon inflation for flow diverter resulting with death.

$85.3 \%$ of the aneurysms were located on anterior circulation and $14.7 \%$ of the aneurysms were located on posterior circulation. $22.4 \%$ of the aneurysms were located distally and $77.6 \%$ of the aneurysms were located proximal to the Circle of Willis.

Adverse event rate was significantly lower in the second 58 procedures as compared to the first 58 (11 versus 2, p: $0.013)$. These two groups were not significantly different in terms of age, sex and aneurysm size. At the beginning of the experience, the devices were deployed strictly by pushing the stent out/pulling the catheter back and once it apposed the vessel wall, by pushing out the stent only. The techniques 
Gurkas E. et al: Silk Device for Intracranial Aneurysm Treatment

Table I: Mean and Median Aneurysm Sizes in Patients with and without Complications

\begin{tabular}{|c|c|c|c|}
\hline & \multicolumn{2}{|c|}{ Aneurysm Size } & \multirow{2}{*}{$\mathbf{p}$} \\
\hline & Mean $\pm S S$ & Median [Min - Max] & \\
\hline Without complication $(n=96)$ & $9.5 \pm 6.3$ & $8[2-30]$ & \multirow{2}{*}{0.015} \\
\hline With complication $(n=13)$ & $18.0 \pm 10.8$ & $20[3-32]$ & \\
\hline
\end{tabular}

for device deployment as mentioned above were refined with increasing experience.

The plot in figure 10 shows the cumulative proportion of cases with adverse event by number of patients treated (operator experience). The proportion with complications decreases with increasing physician experience.

The learning curve plot suggested that for our interventional team the adverse event rate was stabilized at around 50 patients.

Since aneurysm size is known to be a significant determinant of adverse events, we compared the first 58 patients to the second 58 in terms of size and found no statistically significant difference between two groups $(p=0.26)$. Interestingly, overall complication rates significantly increased as the aneurysm size increased (Table I). Cut-off value for aneurysm size predicting complication occurrence was $18.5 \mathrm{~mm}$ with $61.5 \%$ sensitivity and $90.6 \%$ specificity.

\section{DISCUSSION}

Various published reports have shown that flow diverter use is a safe and effective way of treatment for intracranial aneurysm treatment. Initial experiences came from large single center studies and multicenter registries $(9,17,20,25,30)$. Aneurysm occlusion rates of approximately $90 \%$ were achieved at 6 months. Morbidity and mortality rates of $0-6.8 \%$ and minor complication rates of $11 \%$ have been reported. The pipeline embolization device (PED) for the Intracranial Treatment of Aneurysms (PITA) trial was a multicenter single-arm nonrandomized clinical trial conducted at three European centers and one center in Argentina in 31 patients with 31 aneurysms that were wide-necked or had failed previous endovascular treatment. In this trial, a total of 47 devices were placed with a mean of 1.52 devices per aneurysm. A single PED was used in 18 of the 31 cases (58.1\%). PED placement was technically successful in 30 of the 31 aneurysms (96.8\%). Severe complications of major stroke occurred in two patients $(6.5 \%)$, with no reported minor strokes (25). Saatci et al. reported a $14 \%$ complication rate in a large series of 191 patients treated with the PED, resulting in permanent morbidity in $1 \%$ and death in $0.5 \%$ (28). Results from the Pipeline for Uncoilable or Failed Aneurysms (PUFS) trial, which included eight investigational sites in the USA and two international sites, demonstrated that PED placement was technically successful in 107 of 108 patients (99.1\%), stroke occurred in 8/107 patients $(7.5 \%)$ and major ipsilateral stroke or death occurred in $6 / 107$ patients $(5.6 \%)(3)$. The results of our study in terms of technical success, morbidity, mortality and complication rates were consistent with the previous trials. Although an 11.2 percent complication rate appears to be higher than anticipated, it should be noted that almost half of the adverse events resulted in either no or mild clinical sequela in the early post-procedure period. Another point to keep in mind is that $38 \%$ of the aneurysms we treated were either large or giant.

In many studies, aneurysm size was related with aneurysm recurrence, that is, aneurysms with a diameter $>10 \mathrm{~mm}$ have a higher rate of recurrence $(21,33)$. In few separate studies the effect of aneurysm size on complication rates were reported. In a study by Chalouhi et al., safety and efficacy of 100 small intracranial aneurysms were evaluated and symptomatic procedure-related complications occurred in 3 patients (3\%) with a high favorable outcome in the latest follow-up (5). In another study, Lin et al. demonstrated only one complication in 41 patients with 44 aneurysms $<10 \mathrm{~mm}$. (13). In the PUFS (Pipeline for Uncoilable or Failed Aneurysms) trial, which only included large and giant aneurysms, the major stroke or neurological death rate was only $5.6 \%$ (25). Chalouhi et al. found that PED treatment provided similar complication rates for large and giant aneurysms (4). Taken together with our results, these data support the increasing complication rates with large and giant aneurysms with a cut-off aneurysm size of $18.5 \mathrm{~mm}$.

Learning curve for neurointerventional procedures is a known entity but its importance is not emphasized enough even in controlled studies. Stenting at the level of the common carotid artery bifurcation (CAS) has been the grounds of discussions related to the learning curve in endovascular neurologic interventions. Significant controversy existed as to the caseload necessary for an appropriate learning curve before systematic use of carotid stenting (32). With widespread adoption of stenting, a learning curve in carotid stenting became a well-recognized phenomenon (14). Indeed, failure of acknowledgement of this fact led to premature halting of 2 randomized trials comparing stenting and endarterectomy $(1,24)$. Similarly EVA3S and SPACE trials are criticized for allowing inexperienced operators to perform CAS against better trained surgeons performing endarterectomy and the balanced results in CREST study, which allowed CAS to find its current place in treatment guidelines, is attributed to meticulous selection and training of CAS operators $(7,19,31)$. $A$ recent study showed that institutional experience is related to a significant decrease in mortality and morbidity of CAS and an operator experience of at least 72 cases is required to attain acceptable levels of morbidity and mortality (10). The critical importance of institutional besides the operator experience was also stated by a meta-analysis performed 
Gurkas E. et al: Silk Device for Intracranial Aneurysm Treatment

on this subject (29) and a recent paper on learning curves in CAS (26). This data lead to a multispecialty consensus on the requirement of at least 75 CAS procedures (50 of them as the primary operator) to start CAS and 50 CAS procedures annually further on to maintain competence (6).

Clearly, endovascular treatment of intracranial aneurysms is technically more complex, demanding a higher level of expertise and dexterity as compared to carotid stenting. Yet, the consequences of the learning curve have been ignored for the most part in interventional neuroradiology. Per some vendors, a requirement of as low as 5 proctored cases per new operator is enough for starting flow diverter placement. The physicians, likewise, have underrated the effect of the learning curve. For instance, Murthy et al. published two separate review papers for Pipeline and Silk devices individually based on their evaluation of the earlier reports on either device $(22,23)$. In the latter paper they scrutinized the Silk device and concluded that the Pipeline device is safer. A detailed evaluation of their analysis shows that a considerable number of patients included in their Pipeline report were performed by interventional groups with prior flow diverter experience with Silk (15), the first commercially available flow diverter. That is to say, their comparison may, at least partly, support the effect of the flow diverter learning curve. This point is not unique to Silk device, a similar learning curve was also described for the Pipeline device by groups starting flow diverter placement directly with this device without prior experience on other flow diverters (11). One point that contradicts with this assumption is the increasing morbidity and mortality rates of some interventional groups included in the literature review after the publication of the review paper (eg from $0 \%$ to $6.3 \%$ ) (16). Although this appears to contradict with the concept of the learning curve, a detailed evaluation of the first manuscript by Murthy et al. reveals that the majority of the reports included in the Pipeline series represent data from carefully controlled (pre-commercialization) device evaluation studies and/or vendor sponsored studies for regulatory approval of the device (such as PITA or PUFS studies) which may inherently contain bias $(2,3,18,25)$ whereas those listed in the Silk report provide "real-life" results with lesser tendency for "cherry picking" of more suitable aneurysms. The inclusion of cases outside the context of trials may have result an increase in the morbidity and mortality rate. As a matter of fact, in a recent retrospective multicenter study involving 17 centers, 5 of which were included in the paper by Murthy (which itself involved 12 centers) the neurologic morbidity and mortality rate was $8.4 \%$ (12). All things considered, we put forward that further studies comparing flow diverters to each other or to other treatment modalities including stents should take the learning curve into consideration. In our study, we observed the same learning curve as shown in figure 10 and adverse event rates were significantly different between the first half and second half of the procedures $(18.9 \%$ vs $3.4 \%$, respectively). Based on our results and others (30), it is reasonable to mandate the inclusion of operators with at least 50 to 100 personal cases should be included in these studies. Additionally, curriculum of subspecialty training in endovascular neurologic procedures should include enough exposure to this technique.

Throughout the learning period, to pay attention to some technical points which we believe to have helped us can lower the rate of adverse events. First of all determining the stent size is critical. In our opinion, choosing the stent according to the measurements of the fully deployed and shortened stent length will increase the accuracy of the stent placement. For example, we prefer to deploy a mildly undersized stent of $3.5 \mathrm{~mm}$ for a carotid siphon. Secondly, in case of vascular tortuosity, in order we currently place the microcatheter tip distal to the segment we plan to stent and if possible, on a straight arterial segment. We found that this maneuver not only makes initiation of deployment easier, but also prevents inadvertent proximal migration of the whole system during deployment. Thirdly, deployment of the device one segment at a time will simplify the procedure. If there is an insufficiently expanded segment, this part has to be re-sheathed and deployed again properly or has to expand secondarily by maneuvers explained above. Otherwise, non-apposition or hourglass configuration may develop. Stent apposition is also another important factor affecting treatment outcome. Therefore, stent apposition should be revised after stent detachment and if apposition is not sufficiently attained, use of balloon or stents, apposition should be considered for this purpose. As an exception, if there is contrast stagnation inside the aneurysm when stent is deployed then minimal malapposition is of little importance. Fourthly, distal access catheters provided marked ease during stent deployment and stent re-crossing especially in cases with tortuous anatomy. Additionally, the Silk device is unique for the availability of a tapered configuration. We prefer the tapered version if there is a significant discrepancy in the size of the vessel distal to the aneurysm (or a straightforward stenosis) as compared to the proximal. In our experience this is a frequent finding in dissecting type aneurysms. Finally, the last but not least, telescoping FDs should be avoided as much as possible in perforator rich vascular segments as perforator infarcts may occur due to the higher strut density of FDS compared to other stents. In our cohort, coupling the Silk device with a scaffolding stent or use of a single stent for apposing a Silk device in a perforator rich area is well tolerated.

\section{- CONCLUSION}

Safety of FD placement for intracranial aneurysms increases with experience and smaller size of the aneurysm. Based on our findings, we suggest that the current recommendations for the accreditation of training programs in endovascular management of cerebrovascular diseases and relevant fellowship curricula be revised to include criteria specific to flow diverters in addition to the current recommendations. Moreover, studies comparing flow diverters with other methods or comparing two flow diverters need to include institutions with sufficient experience. 


\section{- REFERENCES}

1. Alberts M: Results of a multicenter prospective randomized trial of carotid artery stenting vs. carotid endarterectomy. Stroke 32:325, 2001

2. Amiri AR, Kanesalingam K, Cro S, Casey AT: Does source of funding and conflict of interest influence the outcome and quality of spinal research? Spine J 14(2):308-314,2014

3. Becske T, Kallmes DF, Saatci I, McDougall CG, Szikora I, Lanzino G, Moran CJ, Woo HH, Lopes DK, Berez AL, Cher DJ, Siddiqui AH, Levy El, Albuquerque FC, Fiorella DJ, Berentei Z, Marosfoi M, Cekirge SH, Nelson PK: Pipeline for uncoilable or failed aneurysms: Results from a multicenter clinical trial. Radiology 267(3):858-868, 2013

4. Chalouhi N, Tjoumakaris S, Starke RM, Gonzalez LF, Randazzo C, Hasan D, McMahon JF, Singhal S, Moukarzel LA, Dumont AS, Rosenwasser R, Jabbour P: Comparison of flow diversion and coiling in large unruptured intracranial saccular aneurysms. Stroke 44(8):2150-2154, 2013

5. Chalouhi N, Zanaty M, Whiting A, Yang S, Tjoumakaris S, Hasan D, Starke RM, Hann S, Hammer C, Kung D, Rosenwasser R, Jabbour P: Safety and efficacy of the Pipeline Embolization Device in 100 small intracranial aneurysms. J Neurosurg 122(6):1498-1502, 2015

6. Cremonesi A, Setacci C, Bignamini A, Bolognese L, Briganti F, Di Sciascio G, Inzitari D, Lanza G, Lupattelli L, Mangiafico S, Pratesi C, Reimers B, Ricci S, de Donato G, Ugolotti U, Zaninelli A, Gensini GF: Carotid artery stenting: First consensus document of the ICCS-SPREAD Joint Committee. Stroke 37(9):2400-2409, 2006

7. Eckstein $\mathrm{HH}$, Ringleb $\mathrm{P}$, Allenberg JR, Berger J, Fraedrich G, Hacke W, Hennerici M, Stingele R, Fiehler J, Zeumer H, Jansen O: Results of the Stent-Protected Angioplasty versus Carotid Endarterectomy (SPACE) study to treat symptomatic stenoses at 2 years: A multinational, prospective, randomised trial. Lancet Neurol 7(10):893-902, 2008

8. Ferns SP, Sprengers ME, van Rooij WJ, Rinkel GJ, van Rijn JC, Bipat S, Sluzewski M, Majoie CB: Coiling of intracranial aneurysms: A systematic review on initial occlusion and reopening and retreatment rates. Stroke 40:523-29, 2009

9. Fiorella D, Woo HH, Albuquerque FC, Nelson PK: Definitive reconstruction of circumferential, fusiform intracranial aneurysms with the pipeline embolization device. Neurosurgery 62:1115-1120, 2008

10. Gray WA, Rosenfield KA, Jaff MR, Chaturvedi S, Peng L, Verta P; CAPTURE 2 Investigators and Executive Committee: Influence of site and operator characteristics on carotid artery stent outcomes: Analysis of the CAPTURE 2 (Carotid ACCULINK/ACCUNET Post Approval Trial to Uncover Rare Events) clinical study. JACC Cardiovasclnterv 4(2):235-246, 2011

11. Jabbour P, Chalouhi N, Tjoumakaris S, Gonzalez LF, Dumont AS, Randazzo C, Starke RM, Hasan D, Chitale R, Singhal S, Moukarzel LA, Rosenwasser R: The pipeline embolization device: Learning curve and predictors of complications and aneurysm obliteration. Neurosurgery 73(1):113-120, 2013
12. Kallmes DF, Hanel R, Lopes D, Boccardi E, Bonafé A, Cekirge $S$, Fiorella $D$, Jabbour $P$, Levy $E$, McDougall $C$, Siddiqui $A$, Szikora I, Woo H, Albuquerque F, Bozorgchami H, Dashti SR, Delgado Almandoz JE, Kelly ME, Turner R $4^{\text {th }}$, Woodward BK, Brinjikji W, Lanzino G, Lylyk P: International retrospective study of the pipeline embolization device: A multicenter aneurysm treatment study. AJNR Am J Neuroradiol 36(1):108-115, 2014

13. Lin LM, Colby GP, Kim JE, Huang J, Tamargo RJ, Coon AL: Immediate and follow-up results for 44 consecutive cases of small $(<10 \mathrm{~mm})$ internal carotid artery aneurysms treated with the pipeline embolization device. Surg Neurol Int 4:114, 2013

14. Lin PH, Bush RL, Peden E, Zhou W, Kougias P, Henao E, Mohiuddin I, Lumsden AB: What is the learning curve for carotid artery stenting with neuroprotection? Analysis of 200 consecutive cases at an academic institution. Perspect Vasc Surg Endovasc Ther 17(2):113-123, 2005

15. Lubicz B, Van der Elst O, Collignon L, Mine B, Alghamdi F: Silk flow-diverter stent for the treatment of intracranial aneurysms: A series of 58 patients with emphasis on long-term results. AJNR Am J Neuroradiol 36(3):542-546, 2015

16. Lundquist J, Scrivano E, Ceratto R, Ferrario A, Chudyk J, Bleise C, Orozco F, Lylyk P: Endovascular treatment results with the Flow Diverter Embolization Device (PED) in large and giant intracranial aneurysms. Interv Neuroradiol 19 Suppl 1: 161 0543, 2013

17. Lylyk P, Miranda C, Ceratto R, Ferrario A, Scrivano E, Luna HR, Berez AL, Tran Q, Nelson PK, Fiorella D: Curative endovascular reconstruction of cerebral aneurysms with the pipeline embolization device: The Buenos Aires experience. Neurosurgery 64:632-642, 2009

18. Mansi BA, Clark J, David FS, Gesell TM, Glasser S, Gonzalez J, Haller DG, Laine C, Miller CL, Mooney LA: Ten recommendations for closing the credibility gap in reporting industry-sponsored clinical research: A Joint Journal and Pharmaceutical Industry Perspective. Mayo Clin Proc 87(5): 424-429, 2012

19. Mas JL, Trinquart L, Leys D, Albucher JF, Rousseau H, Viguier A, Bossavy JP, Denis B, Piquet P, Garnier P, Viader F, Touzé $E$, Julia $P$, Giroud $M$, Krause $D$, Hosseini $H$, Becquemin JP, Hinzelin G, Houdart E, Hénon H, Neau JP, Bracard S, Onnient Y, Padovani R, Chatellier G; EVA-3S investigators: Endarterectomy versus angioplasty in patients with symptomatic severe carotid stenosis (EVA-3S) trial: Results up to 4 years from a randomised, multicentre trial. Lancet Neurol 7(10):885-892,2008

20. McAuliffe W, Wycoco V, Rice H, Phatouros C, Singh TJ, Wenderoth $\mathrm{J}$ : Immediate and midterm results following treatment of unruptured intracranial aneurysms with the pipeline embolization device. AJNR Am J Neuroradiol 33:164170,2012

21. Murayama Y, Nien YL, Duckwiler G, Gobin YP, Jahan R, Frazee J, Martin N, Viñuela F: Guglielmi detachable coil embolization of cerebral aneurysms: 11 years' experience. J Neurosurg 98:959-966, 2003

22. Murthy SB, Shah S, Shastri A, Venkatasubba Rao CP, Bershad EM, Suarez JI: The SILK flow diverter in the treatment of intracranial aneurysms. J Clin Neurosci 21(2):203-206, 2014 
Gurkas E. et al: Silk Device for Intracranial Aneurysm Treatment

23. Murthy SB, Shah S, VenkatasubbaRao CP, Bershad EM, Suarez Jl: Treatment of unruptured intracranial aneurysms with the pipeline embolization device. J Clin Neurosci 21(1): 6-11, 2014

24. Naylor AR, Bolia A, Abbott RJ, Pye IF, Smith J, Lennard N, Lloyd AJ, London NJ, Bell PR: Randomized study of carotid angioplasty and stenting versus carotid endarterectomy: A stopped trial. J Vasc Surg 28(2):326-334, 1998

25. Nelson PK, Lylyk P, Szikora I, Wetzel SG, Wanke I, Fiorella D: The pipeline embolization device for the intracranial treatment of aneurysms trial. AJNR Am J Neuroradiol 32(1):34-40, 2011

26. Parlani G, De Rango P, Verzini F, Cieri E, Simonte G, Casalino A, Manzone A, Cao P: Safety of carotid stenting (CAS) is based on institutional training more than individual experience in large-volume centres. Eur J Vasc Endovasc Surg 45(5): 424-430, 2013

27. Raymond J, Guilbert F, Weill A, Georganos SA, Juravsky L, Lambert A, Lamoureux J, Chagnon M, Roy D: Long-term angiographic recurrences after selective endovascular treatment of aneurysms with detachable coils. Stroke 34:1398-1403,2003

28. Saatci I, Yavuz K, Ozer C, Geyik S, Cekirge HS: Treatment of intracranial aneurysms using the Pipeline flow-diverter embolization device: A single-center experience with longterm follow-up results. AJNR Am J Neuroradiol 33(8):14361446, 2012
29. Smout J, Macdonald S, Weir G, Stansby G: Carotid artery stenting: Relationship between experience and complication rate. Int J Stroke 5(6):477-482, 2010

30. Szikora I, Berentei Z, Kulcsar Z, Marosfoi M, Vajda ZS, Lee W, Berez A, Nelson PK: Treatment of intracranial aneurysms by functional reconstruction of the parent artery: The Budapest experience with the pipeline embolization device. AJNR Am J Neuroradiol 31: 1139-1147, 2010

31. Thomas GB, Hobson II RW, Howard G, Roubin GS, Clark WM, Brooks W, Mackey A, Hill MD, Leimgruber PP, Sheffet AJ, Howard VJ, Moore WS, Voeks JH, Hopkins LN, Cutlip DE, Cohen DJ, Popma JJ, Ferguson RD, Cohen SN, Blackshear JL, Silver FL, Mohr JP, Lal BK, Meschia JF; CREST Investigators: Stenting versus endarterectomy for treatment of carotidartery stenosis. N Engl J Med 363(1):11-23, 2010

32. Verzini F, Cao P, De Rango P, Parlani G, Maselli A, Romano L, Norgiolini L, Giordano G: Appropriateness of learning curve for carotid artery stenting: An analysis of periprocedural complications. J Vasc Surg 44(6):1205-1211, 2006

33. Yadla S, Campbell PG, Grobelny B, Jallo J, Gonzalez LF, Rosenwasser $\mathrm{RH}$, Jabbour PM: Open and endovascular treatment of unruptured carotid-ophthalmic aneurysms: Clinical and radiographic outcomes. Neurosurgery 68: 1434-1443, 2011 